\title{
Pengaruh Temperatur Solution Treatment dan Aging terhadap Fasa Dan Kekerasan Copperized-AISI 1006
}

\author{
Widia Anggia Vicky, Sutarsis, dan Hariyati Purwaningsih \\ Jurusan Teknik Material dan Metalurgi, Fakultas Teknologi Industri, Institut Teknologi Sepuluh \\ Nopember (ITS) \\ Jl. Arief Rahman Hakim, Surabaya 60111 Indonesia \\ e-mail: sutarsis@mat-eng.its.ac.id
}

\begin{abstract}
Abstrak-Sebagai salah satu unsur paduan yang digunakan pada baja karbon rendah, tembaga dapat meningkatkan kekuatan tanpa menurunkan keuletan secara signifikan. Tembaga meningkatkan kekuatan pada baja dengan mekanisme penguatan secara precipitation hardening. Dalam penelitian ini dilakukan pemaduan tembaga dan baja AISI 1006 dengan mencelupkan baja AISI 1006 yang telah di-pre-heat ke dalam tembaga cair. Selanjutnya dilakukan precipitation hardening dengan variasi pada temperatur solution treatment dan aging. Dari hasil penelitian ini didapatkan bahwa temperatur solution treatment tidak mempengaruhi fasa yang terbentuk pada copperized-AISI 1006, yaitu tetap berupa $\alpha$-ferit. Selain itu kenaikan dari temperatur solution treatment berbanding terbalik dengan nilai kekerasan dan temperatur aging $4^{\circ} 0^{\circ} \mathrm{C}$ menghasilkan kekerasan tertinggi dibanding temperatur aging yang lain, yaitu 119, 47 VHN dan 115,75 VHN untuk sampel yang sebelumnya di-solution treatment 800 dan $900^{\circ} \mathrm{C}$.
\end{abstract}

Kata Kunci-copperizing, solution treatment, aging, AISI 1006, fasa, kekerasan, precipitation hardening

\section{PENDAHULUAN}

$\mathrm{P}$ ADA saat ini tembaga menjadi salah satu material yang berkembang pesat dan banyak digunakan sebagai logam berat non-ferrous [1]. Tembaga banyak digunakan karena memiliki konduktivitas listrik dan panas yang baik, ketahan korosi yang baik, mudah difabrikasi, serta memiliki kekuatan dan ketahanan fatigue yang baik [2]. Pada umumnya tembaga dipadukan dengan timah, sehingga didapat paduan yang kita kenal dengan sebutan perunggu. Selain itu tembaga juga sering dipadukan dengan seng untuk menghasilkan kuningan. Keuntungan dari paduan-paduan ini akan meningkatkan sifat mekanik dari tembaga itu sendiri. Namun, selain dengan kedua unsur diatas tembaga juga dipadukan dengan baja selaku logam yang umum penggunaannya. Penggunaan tembaga dalam pemaduan ini dapat meningkatkan kekuatan, namun mempertahankan keuletannya, berbeda dengan karbida dan nitrida [3].
Penurunan keuletan pada baja ini umumnya terjadi pada metode pengerasan yang biasa dilakukan, yaitu penambahan karbon (carburising) atau pun penambahan nitrogen (nitriding) [4]. Akan tetapi, dengan penambahan unsur tembaga di dalam baja sebagai paduan akan menurunkan sifat mekaniknya apabila kadarnya tidak dikontrol [5].

Pada penelitian ini akan dilakukan metode pemaduan baja dengan tembaga dengan mengadopsi metode hot-dip coating, yakni dengan mencelupkan baja yang telah di-preheat ke dalam tembaga cair. Metode ini selanjutnya akan disebut dengan coperrizing. Copperizing sendiri sudah pernah dilakukan oleh Isori [6] dan Kevin [7]. Setelah proses copperizing akan dilanjutkan dengan presipitaion hardening yang terdiri dari solution treatment dan aging. Pengaruh dari variasi temperatur solution treatment dan aging terhadap fasa dan kekerasan copperized-AISI 1006 akan dianalisis lebih lanjut dengan berbagai pengujian.

\section{METODOLOGI}

Material yang digunakan pada penelitian ini adalah AISI 1006 dengan komposisi yang dicantumkan pada tabel 1. Baja AISI 1006 yang berupa plat disiapkan menjadi beberapa spesimen dengan dimensi panjang rata-rata $70 \mathrm{~mm}$. Tembaga yang dipakai memiliki kemurnian 99,9\%. Copperizing dilakuakan dengan menggunakan muffle furnace. Sampel baja yang telah di-pre-heat dicelupkan ke dalam tembaga cair selama 5 menit dan diikuti dengan pendinginan dengan media udara. Copperized-AISI 1006 dipanaskan kembali dengan variasi temperatur solution treatment 800 dan $900^{\circ} \mathrm{C}$. Kemudian masing-masing sampel solution treatment di-aging dengan variasi temperatur 400,450 , dan $500^{\circ} \mathrm{C}$. Selanjutnya dilakukan pengamatan makro, pengujian spektroskopi, XRD, dan uji kekerasan. 


\section{HASIL DAN DISKUSI}

\section{A. Pengamatan Makro}

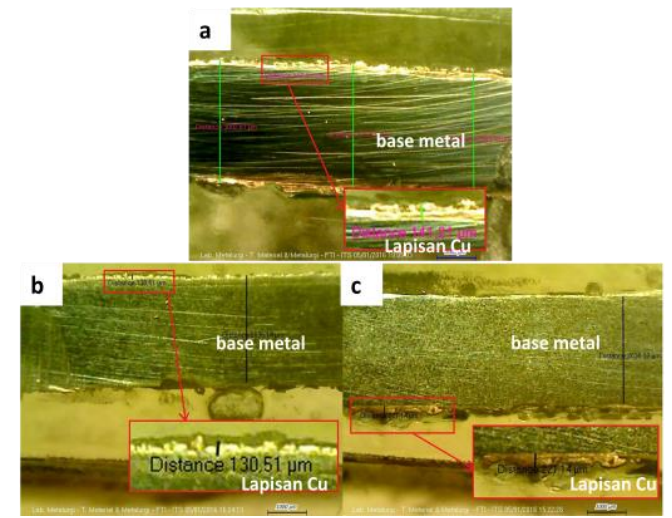

Gambar 1. Penampang Melintang (a) Copperized-AISI 1006, (b) SolutionTtreatment $900^{\circ} \mathrm{C}$, dan (c) Solution treatment $800^{\circ} \mathrm{C}$

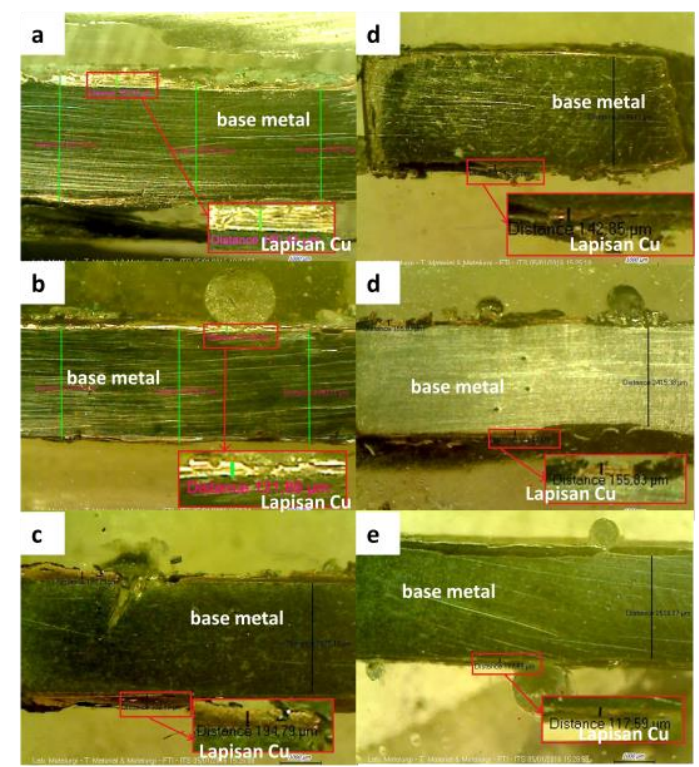

Gambar 2. Penampang Melintang Sampel SolutionTtreatment $800^{\circ} \mathrm{C}$ dengan Aging (a) $400^{\circ} \mathrm{C}$, (b) $450^{\circ} \mathrm{C}$, (c) $500^{\circ} \mathrm{C}$, dan SolutionTtreatment $900^{\circ} \mathrm{C}$ dengan Aging (d) $400^{\circ} \mathrm{C}$, (e) $450^{\circ} \mathrm{C}$, dan (f) $500^{\circ} \mathrm{C}$

Dari Gambar 1 terlihat adanya lapisan tembaga yang terdapat pada bagian permukaan baja setelah di-copperizing. Hal tersebut terjadi karena adanya tembaga yang belum terdifusi ke dalam baja ketika sampel diangkat dari tembaga cair, sehingga tembaga membentuk lapisan pada permukaan sampel.

Lapisan tembaga juga masih terlihat pada permukaan sampel setelah di-solution treatment. Adanya lapisan tembaga juga masih nampak pada sampel setelah dilakukan proses aging seperti pada Gambar 2. Hal tersebut mengindikasikan bahwa pemanasan yang terjadi selama solution treatment dan aging belum mampu mendifusikan tembaga yang ada di permukaan baja setelah copperizing. Dari gambar terlihat adanya lapisan tembaga dengan berbagai ketebalan yang tidak membentuk hubungan dengan temperatur solution treatment dan aging yang dilakukan.

\section{B. Pengujian Komposisi Kimia}

Tabel 1.

Komposisi Sampel Sebelum dan Sesudah Copperizing

\begin{tabular}{lcccccc}
\hline \hline \multicolumn{7}{c}{ Komposisi, \% } \\
\hline & $\mathrm{Fe}$ & $\mathrm{C}$ & $\mathrm{Mn}$ & $\mathrm{Cu}$ & $\mathrm{P}$ & $\mathrm{S}$ \\
\hline AISI 1006 & 99,5 & 0,0358 & 0,210 & 0,0375 & 0,0091 & 0,008 \\
$\begin{array}{c}\text { Copperized- } \\
\text { AISI 1006 }\end{array}$ & 99,4 & 0,0721 & 0,218 & 0,0860 & 0,0142 & 0,009 \\
\hline \hline
\end{tabular}

Tabel 1 menunjukkan komposisi unsur-unsur pada baja AISI 1006 sebelum dan sesudah dilakukan proses copperizing. Dari hasil pengujian diperoleh kenaikan kadar $\mathrm{Cu}$ (tembaga) pada baja, dimana sebelum di-copperizing kadar tembaga $0,0375 \%$ dan setelah di-copperizing menjadi 0,0860\%. Hal tersebut menunjukkan terjadinya penambahan kadar tembaga ke dalam baja AISI 1006 sebanyak 0,0485\%.

\section{Pengujian X-Ray Diffraction}

Pengujian XRD dilakukan pada baja AISI 1006 tanpa perlakuan, sampel copperizing, solution treatment, dan aging. Pengukuran difraksi sinar-X dilakukan dengan rentang sudut $10-90^{\circ}$ dan menggunakan panjang gelombang $\mathrm{Cu}-\mathrm{K} \alpha$ 1.54060Á. Dari hasil XRD diperoleh peak-peak dengan intensitas tertentu. Peak-peak yang memiliki intensitas tertinggi dicocokkan dengan kartu PDF untuk mengetahui fasa atau senyawa apa yang terdapat pada sampel.

\section{- Hasil Pengujian XRD baja AISI 1006}

Gambar 3 menunjukkan grafik hasil XRD baja AISI 1006. Dari hasil analisis menunjukkan adanya kecocokkan antara hasil XRD dengan kartu PDF 87-0721 dan didapatkan bahwa ketiga peak tertingginya milik fasa $\mathrm{Fe}-\alpha$. Selain itu mengacu pada diagram fasa $\mathrm{Fe}-\mathrm{Fe}_{3} \mathrm{C}$, baja dengan kadar karbon $0,0375 \%$ memang memiliki fasa yang dominan berupa $\mathrm{Fe}-\alpha$ pada temperatur kamar.

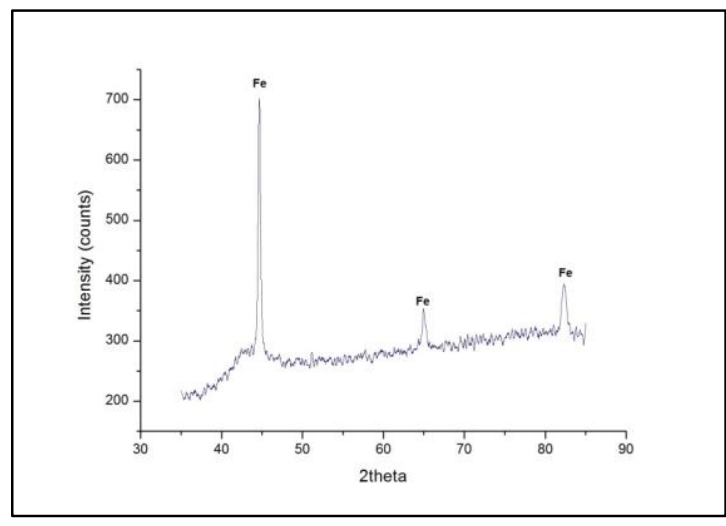

Gambar 3. Grafik Hasil XRD Baja AISI 1006

Peak tertinggi terdapat pada $2 \theta=44,6563^{\circ}$ dengan peak height sebesar 487,49 cts. Untuk peak tertinggi kedua dengan peak height 73,89 cts terletak pada $2 \theta=82,3476^{\circ}$ dan peak tertinggi ketiga memiliki peak height 68,47 cts pada $2 \theta=$ $64,9553^{\circ}$.

\section{- Hasil Pengujian XRD Copperized-AISI 1006}

Hasil pengujian XRD untuk sampel copperized-AISI 1006 dapat dilihat pada Gambar 4. Nilai $2 \theta$ dari peak-peak tertinggi terdapat pada daerah yang sama dengan $2 \theta$ dari baja AISI 
1006. Peak tertinggi terletak pada $2 \theta=44,6594^{\circ}$ dengan peak height 585,4 cts. Peak tertinggi kedua dan ketiga terletak pada $2 \theta=82,2498$ o dan $64,9733^{\circ}$ dengan peak height 124,98 cts dan 92,37 cts. Peak-peak tersebut juga memiliki kecocokan dengan kartu PDF 87-0721 dan merupakan peak milik Fe- $\alpha$. Hasil analisis tersebut sesuai dengan diagram fasa $\mathrm{Fe}-\mathrm{Cu}$, dimana fasa yang dimiliki oleh paduan $\mathrm{Fe}-\mathrm{Cu}$ dengan kadar tembaga yang sangat rendah berupa $\mathrm{Fe}-\alpha$.

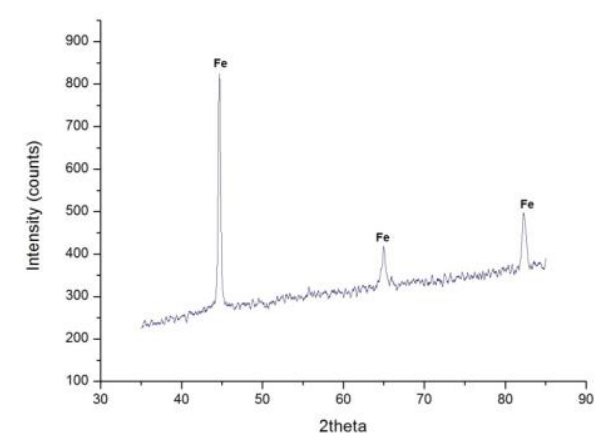

Gambar 4. Grafik Hasil XRD Coperrized-AISI 1006

Dari Tabel 2 tampak adanya perubahan besarnya FWHM (full width at half maximum) pada intensitas tertinggi dari sampel sebelum dan sesudah di-copperizing. Perubahan nilai FWHM menunjukkan adanya peak broadening atau pelebaran puncak dan dapat digunakan untuk menghitung besarnya microstrain. Dari Tabel 2 terlihat adanya kenaikan nilai microstrain dari baja AISI 1006 ke copperized-AISI 1006. Hal tersebut mengindikasikan adanya unsur paduan $(\mathrm{Cu})$ yang terlarut ke dalam $\mathrm{Fe}-\alpha$ setelah baja di-copperizing. Hal tersebut juga sesuai dengan hasil uji spektroskopi yang menunjukkan kenaikan kadar $\mathrm{Cu}$ setelah copperizing.

Tabel 2.

Hasil XRD Baja AISI 1006 dan Copperized-AISI 1006

\begin{tabular}{ccccc}
\hline \hline Sampel & $2 \theta\left({ }^{\circ}\right)$ & Height $(\mathrm{cts})$ & FWHM & $\varepsilon$ \\
\hline AISI 1006 & 44,6563 & 487,49 & 0,0836 & 0,0005 \\
$\begin{array}{c}\text { Copperized- } \\
\text { AISI 1006 }\end{array}$ & 44,6594 & 585,4 & 0,2342 & 0,0041 \\
\hline \hline
\end{tabular}

\section{- Hasil Pengujian XRD Sampel Solution treatment}

Hasil XRD dari sampel solution treatment dapat dilihat pada Gambar 5. Untuk intensitas tertinggi memiliki kesesuaian dengan kartu PDF 87-0721 yang merupakan milik $\mathrm{Fe}-\alpha$. Intensitas tertingi ketiga dan keempat juga bersesuaian dengan puncak milik Fe- $\alpha$. Hal ini sesuai dengan diagram fasa $\mathrm{Fe}-\mathrm{Cu}$, dimana dengan kadar $\mathrm{Cu}$ yang sangat rendah fasa yang terjadi adalah Fe- $\alpha$.

Tetapi, pada hasil XRD kedua sampel solution treatment terdapat peak yang merupakan milik $\mathrm{Cu}$ pada sudut $2 \theta=$ $42,9228^{\circ}$ untuk solution treatment $800^{\circ} \mathrm{C}$ dan $2 \theta=42,7602^{\circ}$ untuk solution treatment $900^{\circ} \mathrm{C}$. Puncak ini bersesuaian dengan kartu PDF 85-1326. Munculnya puncak $\mathrm{Cu}$ ini terjadi karena difusi lanjutan dari $\mathrm{Cu}$ yang terdapat di permukaan sampel selama proses pemanasan solution treatment. Tetapi karena telah melewati batas kelarutan dari $\mathrm{Cu}$ di dalam $\mathrm{Fe}$ maka $\mathrm{Cu}$ yang baru berdifusi tersebut tidak terlarut di dalam larutan padat Fe, tetapi berdifusi ke batas butir. Yourong [8] juga menyatakan dalam penelitiannya bahwa tembaga dapat berdifusi masuk ke dalam butiran ferit atau batas butirnya.

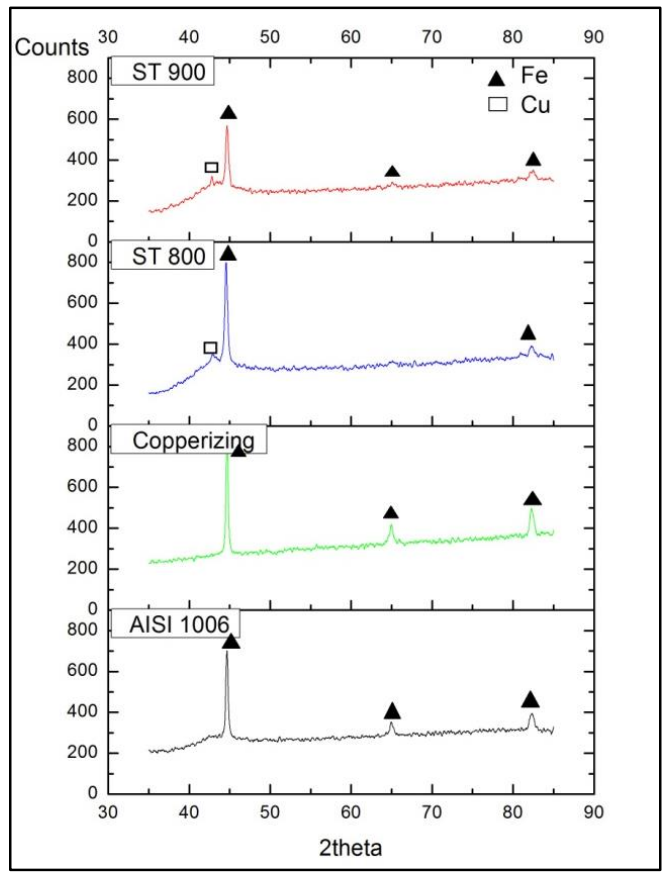

Gambar 5. Hasil XRD Baja AISI 1006, Copperized-AISI 1006, dan Sampel Solution treatment

\section{- Hasil XRD Sampel Aging}

Hasil pengujian XRD dari sampel aging yang sebelumnya di-solution tretament $800^{\circ} \mathrm{C}$ dapat dilihat pada Gambar 6. Dari gambar tersebut nampak adanya peak yang menunjukkan adanya $\mathrm{Cu}$ pada sampel setelah di-aging. Tetapi terjadi anomali pada sampel yang di-aging $400^{\circ}$, dimana tidak terdapat peak $\mathrm{Cu}$ seperti pada sampel lainnya. Jika dilihat dari grafiknya, hasil XRD sampel aging $400^{\circ} \mathrm{C}$ juga memiliki puncak pada $2 \theta$ sekitar $43^{\circ}$, tetapi karena intensitasnya yang sangat rendah sehingga tidak terdeteksi sebagai salah satu peak tertinggi.

Sementara itu hasil pengujian XRD dari sampel aging yang sebelumnya di-solution treatment $900^{\circ} \mathrm{C}$ dapat dilihat pada Gambar 7. Dari gambar tersebut nampak adanya peak milik $\mathrm{Cu}$ pada keseluruhan sampel setelah di-aging.

Berdasarkan hasil pengujian XRD sampel setelah di-aging diperoleh fasa yang dominan adalah $\mathrm{Fe}-\alpha$. Hal tersebut ditunjukkan oleh peak dengan intensitas tertinggi pada semua sampel aging memiliki kesesuaian dengan peak milik Fe- $\alpha$ pada kartu PDF 87-0721. Hal tersebut juga sesuai dengan diagram fasa $\mathrm{Fe}-\mathrm{Cu}$ yang menunjukkan bahwa fasa untuk paduan $\mathrm{Fe}-\mathrm{Cu}$ dengan kadar $\mathrm{Cu}$ yang sangat rendah berupa $\alpha$ ferit. 


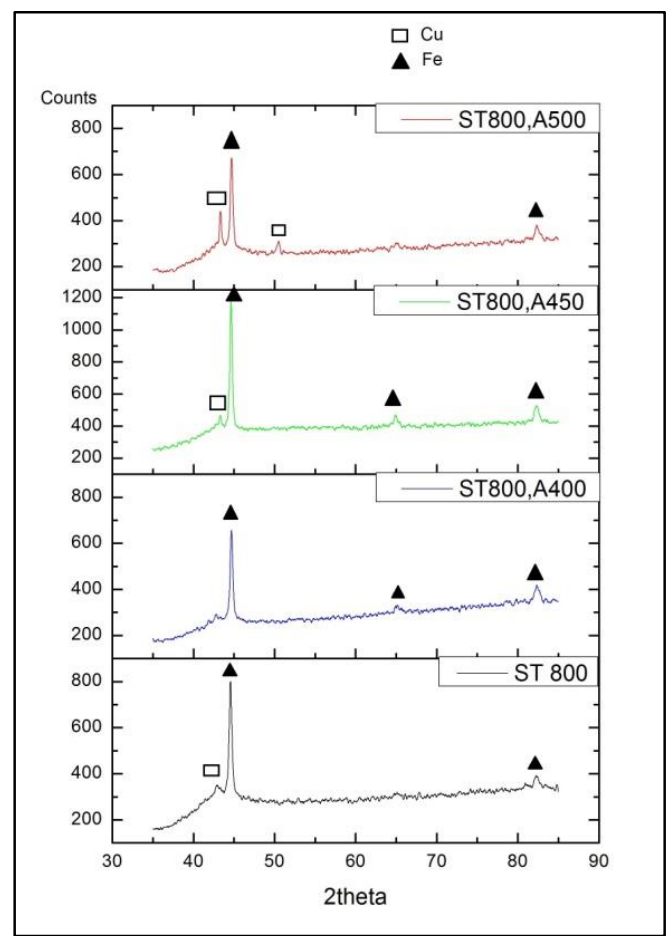

Gambar 6 Hasil XRD Sampel Solution treatment $800^{\circ} \mathrm{C}$ tanpa Aging dan dengan Aging $400,450,500^{\circ} \mathrm{C}$

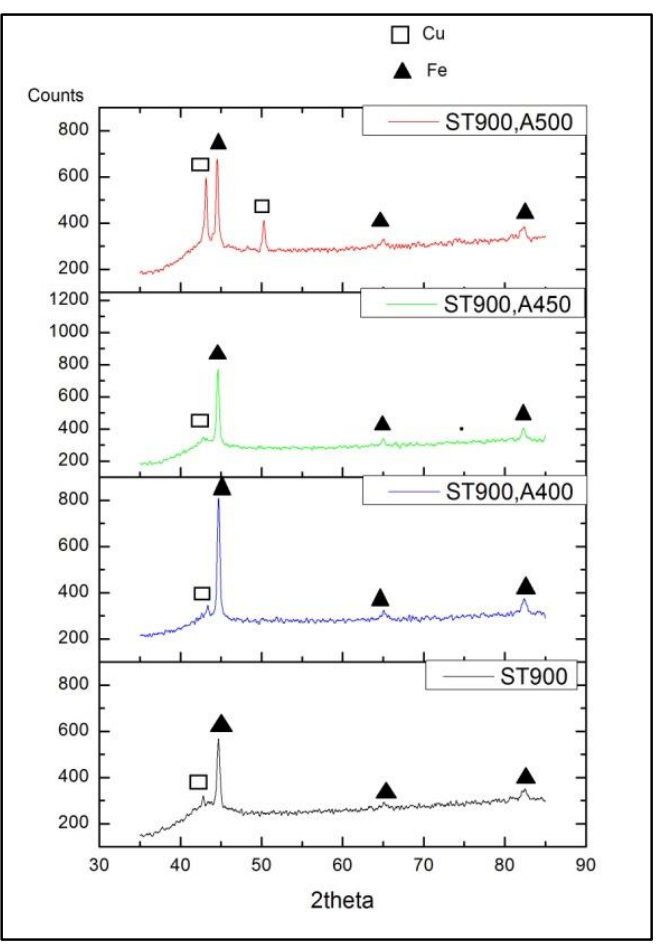

Gambar 7. Hasil XRD Sampel Solution treatment $900^{\circ} \mathrm{C}$ tanpa Aging dan dengan Aging $400,450,500^{\circ} \mathrm{C}$

\section{Hasil Uji Kekerasan}

Pengujian kekerasan dilakukan terhadap fasa $\alpha$-ferit dengan menggunakan metode microhardness (microvickers). Hasil pengujian terhadap baja AISI 1006, copperized-AISI 1006, dan sampel solution treatment dapat dilihat pada Gambar 8 . Nilai kekerasan $\alpha$-ferit mengalami penurunan dari baja AISI
1006 sebesar 127,87 VHN menjadi 122,25 VHN setelah dicopperizing.

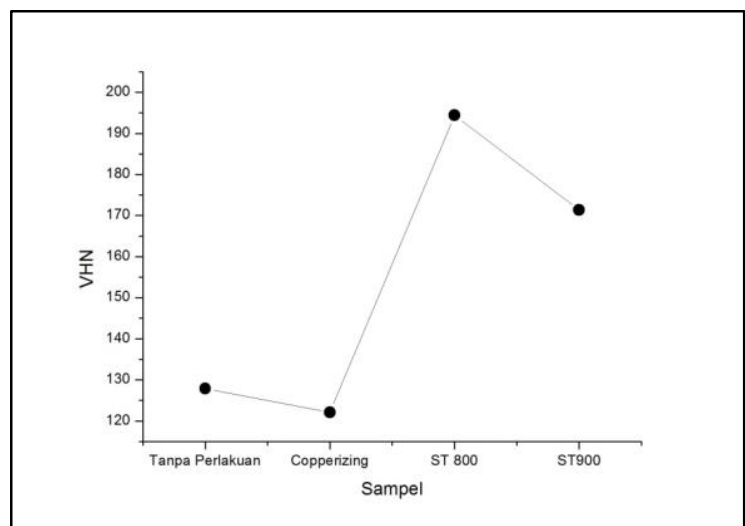

Gambar 8. Nilai Kekerasan Baja AISI 1006, Copperized-AISI 1006, dan Sampel Solution treatment.

Angka kekerasan $\alpha$-ferit mengalami kenaikan setelah sampel di-solution treatment. Dimana sampel yang di-solution treatment pada temperatur $800^{\circ} \mathrm{C}$ memiliki nilai kekerasan sebesar 194,4 VHN dan untuk sampel solution treatment $900^{\circ} \mathrm{C}$ memiliki nilai kekerasan 171,37 VHN. Pengujian kekerasan $\alpha$-ferit selanjutnya dilakukan terhadap sampel aging. Dari hasil pengujian diperoleh penurunan kekerasan dari sampel setelah solution treatment dan setelah aging. Dari hasil penelitian M. Mujahid, dkk [9] juga diperoleh nilai kekerasan maksimum untuk baja dengan kadar karbon 0,3\% yang di-aging pada temperatur $450^{\circ} \mathrm{C}$. Meskipun angka kekerasannya lebih tinggi daripada hasil penelitian ini.

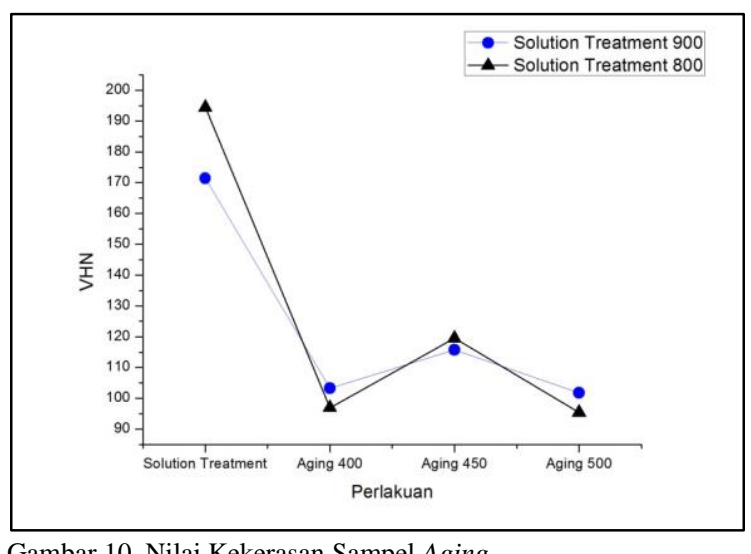

Gambar 10. Nilai Kekerasan Sampel Aging

\section{KESIMPULAN}

Dari hasil penelitian ini dapat disimpulkan bahwa:

1. Temperatur solution treatment dan aging tidak berpengaruh terhadap perubahan fasa copperized-AISI 1006 , dimana fasanya tetap berupa $\alpha$-ferit.

2. Kenaikan temperatur solution treatment berbanding terbalik dengan nilai kekerasan dan temperatur aging $450^{\circ} \mathrm{C}$ menghasilkan nilai kekerasan tertinggi dibanding temperatur aging yang lain, yaitu 119, 47 VHN dan 115,75 
VHN untuk sampel yang sebelumnya di-solution treatment 800 dan $900^{\circ} \mathrm{C}$.

\section{DAFTAR PUSTAKA}

[1] Habashi, Fathi. 1997. Handbook of Extractive Metallutgy Vol 2: Primary Metals, Secondary Metals, Light Metals. Jerman:Wiley-VCH.

[2] 1992. ASM Metals Handbook Vol 2 10th Edition: Properties and Selection Non-Ferrous Alloys and Special Purpose Mate. Ohio: ASM International.

[3] Takaki, Setuo, dkk. 2004. Effect of Copper on Tensile Properties and Grain-Refinement of Steel and its Relation to Precipitation Behaviour. Materials Transactions 45, 7: 2239-2244.

[4] Suherman, Wahid. 2003. Ilmu Logam I. Surabaya: Jurusan Teknik Mesin, FTI-ITS

[5] Sekunowo, Olatunde I, Stephen I. Durowaye, dan Oluwashina P. Gbenebor. 2014. Effect of Copper on Microstructure and Mechanical Properties of Construction Steel. International Journal of Chemical, Molecular, Nuclear, Materials and Metallurgical Engineering 8, 8: 839843.

[6] Dalimonte, Adha I.H., Sutarsis, Agung Purniawan. 2015. Pengaruh Waktu Celup Dan Pendinginan Proses Copperising Plain Carbon Steel Terhadap Struktur Mikro Dan Sifat Mekanik. ITS: Surabaya.

[7] Chaniago, Firstiand Kevin, Sutarsis, Wikan Jatimurti. 2015. Pengaruh Waktu Celup dan Temperatur Pemanasan Awal Proses Copperizing Plain Carbon Steel terhadap Struktur Mikro dan Sifat Mekaniknya. ITS: Surabaya.

[8] Xu, Yourong., dkk. 1993. Diffusion Behaviour of $\mathrm{Fe}$-Cu Interface of Copper Brazed Double-wall Steel Tubes. Material Science Technology 9: 279-282.

[9] Mujahid, M., dkk. 1997. HSLA-100 Steels: Influence of Aging Heat Treatment on Microstructure and Properties. Ohio: ASM Internastional. 